\title{
Drivers and physical processes of drought events over the State of São Paulo, Brazil
}

\author{
Abayomi A. Abatan ${ }^{1}$ (1) - Simon F. B. Tett ${ }^{1} \cdot$ Buwen Dong $^{2} \cdot$ Christopher Cunningham $^{3} \cdot$ Conrado M. Rudorff $^{3}$. \\ Nicholas P. Klingaman ${ }^{2} \cdot$ Rafael C. de Abreu ${ }^{4}$
}

Received: 7 July 2021 / Accepted: 27 November 2021 / Published online: 1 January 2022

(c) Crown 2021

\begin{abstract}
The State of São Paulo, Brazil (SSP) was impacted by severe water shortages during the intense austral summer drought of 2013/2014 and 2014/2015 (1415SD). This study seeks to understand the features and physical processes associated with these summer droughts in the context of other droughts over the region during 1961-2010. Thus, this study examines the spatio-temporal characteristics of anomalously low precipitation over SSP and the associated large-scale dynamics at seasonal timescales, using an observation-based dataset from the Climatic Research Unit (CRU) and model simulation outputs from the Met Office Hadley Centre Global Environment Model (HadGEM3-GA6 at N216 resolution). The study analyzes Historical and Natural simulations from the model to examine the role of human-induced climate forcing on droughts over SSP. Composites of large-scale fields associated with droughts are derived from ERA-20C and ERA-Interim reanalysis and the model simulations. HadGEM3-GA6 simulations capture the observed interannual variability of normalized precipitation anomalies over SSP, but with biases. Drought events over SSP are related to subsidence over the region. This is associated with reduced atmospheric moisture over the region as indicated by the analysis of the vertically integrated moisture flux convergence, which is dominated by reduced moisture flux convergence. The Historical simulations simulate the subsidence associated with droughts, but there are magnitude and location biases. The similarities between the circulation features of the severe 1415SD and other drought events over the region show that understanding of the dynamics of the past drought events over SSP could guide assessment of changes in risk of future droughts and improvements of model performance. The study highlights the merits and limitations of the HadGEM3-GA6 simulations. The model possesses the skills in simulating the large-scale atmospheric circulations modulating precipitation variability, leading to drought conditions over SSP.
\end{abstract}

Keywords Drought $\cdot$ State of São Paulo $\cdot$ Brazil $\cdot$ Large-scale dynamics $\cdot$ Model simulations

\section{Introduction}

The State of São Paulo (Fig. 1; SSP) is located between $20^{\circ}$ and $25^{\circ} \mathrm{S}$ and $53^{\circ}$ and $45^{\circ} \mathrm{W}$ in southeastern Brazil and bordered by the states of Paraná, Mato Grosso do Sul,

Abayomi A. Abatan

yomi.abatan@ed.ac.uk; yomiabatan69@gmail.com

1 School of Geosciences, University of Edinburgh, Edinburgh, UK

2 National Centre for Atmospheric Science and Department of Meteorology, University of Reading, Reading, UK

3 Centro Nacional de Monitoramento e Alertas de Desastres Naturais, São José dos Campos, Brazil

4 Department of Atmospheric Sciences, Universidade de São Paulo, São Paulo, Brazil
Minas Gerais, Rio de Janeiro, and the South Atlantic Ocean (SAO) in the tropics. SSP is home to the largest metropolitan area of Brazil, also named São Paulo, located on a plateau about $800 \mathrm{~m}$ above sea level and about $50 \mathrm{~km}$ away from the SAO. As a result of its location, the city and the state experience a humid subtropical climate and both are vulnerable to the seasonal variability in winds and moisture impacting weather and climate. However, the seasonal variability in precipitation, leading in particular to droughts, can severely affect the water supply system, agriculture, tourism, energy, and other water resource sectors with considerable socioeconomic impacts (Pampuch et al. 2016). For example, drought events can degrade the quality and quantity of drinking water in key reservoirs. Given the high population density of the region and its economic importance for Brazil, a better understanding of the climate variability and 


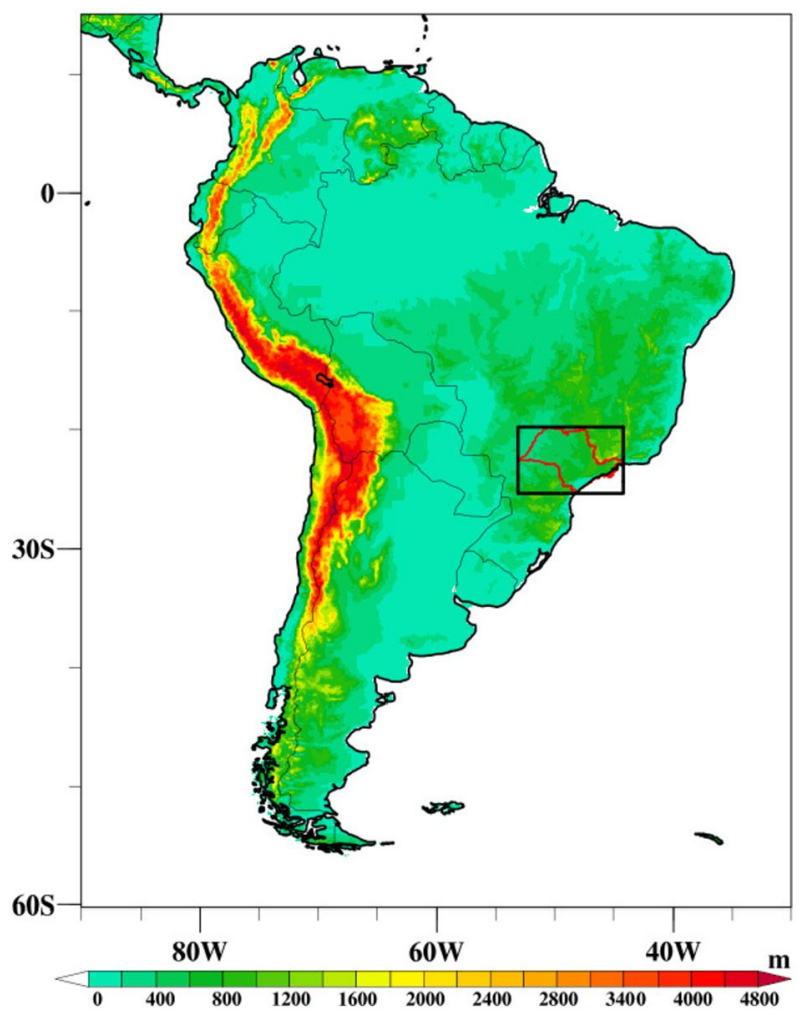

Fig. 1 The topography map (shaded) showing the location of the State of São Paulo (red line). The black box indicates the region used to compute the precipitation time series

associated large-scale mechanisms leading, in particular, to droughts over SSP is needed to guide adaptation and mitigation efforts.

Drought results from precipitation deficits associated with changes in atmospheric dynamics (Abatan et al. 2017). Drought events in southeastern Brazil are widely publicized by the national and international news. For example, beginning from austral summer 2013/2014 to 2014/2015, southeastern Brazil suffered a 16-month drought, and by January 2015, the Cantareira reservoir, the main water storage for the metropolitan area of São Paulo, was down to 5\% of capacity (Nobre et al. 2016; Pattnayak et al. 2018). Debate continues over whether anthropogenic effects influenced this event and the past rainfall variability. Using the Met Office Hadley Centre atmosphere-only general circulation model, HadAM3P, to examine the drivers of 2014/2015 water shortages in southeast Brazil, Otto et al. (2015) concluded that human influences had not affected the risk of precipitation deficit or precipitation minus evaporation (P-E) deficit. de Barros Soares et al. (2017) used the natural-only and historical CMIP5 simulations to examine the anthropogenic influence on changes in precipitation over South America during 1974-2005 and 1955-2005. Significant positive trends in precipitation were found over southern
Brazil, but these authors could not reach a firm conclusion on anthropogenic influence. Liebmann et al. (2001, 2004) showed that observed October-March extreme precipitation had increased. This trend was not due to a change in the timing of the rainy season, but rather from increases in rainy days and the mean rainfall intensity. Thus, it appears that the recent droughts occurred in the context of a general increase in precipitation, and there is yet no consensus on the role of anthropogenic influence.

Climatologically, precipitation in southeast Brazil, which includes the state of São Paulo, shows a maximum in austral summer (Liebmann et al. 2001; Carvalho et al. 2002; Grimm 2003) that arises from the deep convective activity in the South Atlantic Convergence Zone (SACZ; Satyamurty et al. 1998; Marengo et al. 2012; Carvalho et al. 2004). This monsoon-like feature runs from the Amazon basin southeastward through southeast Brazil and out to the subtropical South Atlantic Ocean. Much of the annual rainfall across southeastern Brazil arises from this feature (Garreaud et al. 2009), though some rainfall also comes from frontal systems associated with mid-latitude storms in the South Atlantic, particularly in austral winter. Variability in the SACZ is key to understanding precipitation variability over SE Brazil, but the variability in this system is not well understood. Previous studies show that variations of the SACZ are associated with the El Nino-Southern Oscillation (Garreaud et al. 2009) and the Madden-Julian Oscillation (Alvarez et al. 2016) but with considerable modification by other influences (Silva et al. 2011). Because of the linkage between SACZ and precipitation in SSP, it thus appears that changes in SACZ (which may be associated with changes in other large-scale atmospheric features) may have a significant impact on droughts over SSP during the wet season. Therefore, understanding the dynamics that modulate the SACZ to induce droughts over SSP is important.

Detailed characterization of the extreme precipitation events in SSP have been documented (e.g., Liebmann et al. 2001; Carvalho et al. 2002; Dufek and Ambrizzi, 2008; Marengo et al. 2013; Zilli et al. 2017; and references therein), but there have been fewer studies on austral summer 2013, 2014, and 2015 observed precipitation variability over SSP (e.g., Otto et al. 2015; Coelho et al. 2016a, b; Scricco and Coelho, 2019). Zilli et al. (2017) used stations and gridded precipitation datasets to examine trends in daily extreme precipitation over the southeastern coast of Brazil during 1938-2012. In their study, they found positive trends in average daily precipitation over São Paulo that was due to the increases in frequency and intensity of extreme precipitation events over the region; consistent with the findings from, for example, Teixeira and Satyamurty (2011), Marengo et al. (2013), and Silva Dias et al. (2013). The observed precipitation trends in these studies were limited to the years before 2013. However, Scricco and Coelho (2019) focused their 
summer daily precipitation analysis in the southeast region of São Paulo over the period extending to 2018. In agreement with Coelho et al. (2016a), they indicated that summer 2013/2014 was exceptionally dry. Although the 2014 precipitation deficit was the largest on record since 1961 (Coelho et al. 2016b), other years have also had a drought. For example, there was a sequence of drought events from 1968 to 1972 and a notable drought in 1952 . The main driver of the observed 2013/2014 drought was a long-lasting blocking event, which resulted in a precipitation deficit and enhanced evaporation. Coelho et al. (2016b) concluded that the blocking event was driven by anomalous tropical heat source in Northern Australia/Indonesia, which perturbed the Walker circulation over the tropical Pacific. This, in turn, generated Rossby waves, driving the blocking over SE Brazil. Given the significance of this drought event to the economy of southeast Brazil, it is important to know if the dynamics of the 2013/2014 and 2014/2015 summer drought (hereafter, $1415 \mathrm{SD}$ ) is similar to other summer droughts over the region.

Most of the above-discussed studies were based only on observational analysis. However, large-scale dynamics of the precipitation variability over SSP using model simulation is yet to be further explored. The principal objectives of this paper are to (1) examine the temporal variation of precipitation and identify the 10 driest years in the historical record over SSP; (2) understand the large-scale mechanisms related to seasonal dry extremes; (3) test if model simulations of a high-resolution atmospheric model can reproduce observed droughts and associated mechanisms. In Sect. 2 of this paper, we describe the sources of precipitation and reanalysis data. Section 3 gives the results of the spatial and temporal patterns of precipitation extremes and also examines the mechanisms associated with the dry events at the seasonal time scale. Concluding remarks are presented in Sect. 4

\section{Data and analytical methods}

\subsection{Data and analysis methods}

This study analyses observed and simulated monthly precipitation data to define drought episodes over SSP. The observed precipitation dataset used is that of Harris et al. 2014 (CRU; Climatic Research Unit) which is available on a spatial resolution of $0.5^{\circ}$ latitude $\times 0.5^{\circ}$ longitude for the period January 1901-2016. The simulated precipitation and atmospheric variables are from the 15 ensemble members of the Met Office's Global Environment Model version 3 Global Atmosphere 6.0 at $\mathrm{N} 216$ (approximately $0.56^{\circ}$ latitude $\times 0.83^{\circ}$ longitude) horizontal resolution (HadGEM3GA6; Walters et al. 2017; Christidis et al. 2013). This study uses outputs from Historical (including both natural and historical anthropogenic forcings) and Natural (natural forcings-only) simulations forced by prescribed SST (HadISST) and historical (CMIP5) forcing conditions (Ciavarella et al. 2018). These simulations are available from 1960 to 2014. We further take advantage of the 105 ensemble members of the Historical and Natural experiments available from 2014 to 2015 to examine mechanisms of the 2013/2014 and 2014/2015 summer drought.

The water year calendar in São Paulo runs from September to August (Melo et al. 2016), so we focus our analysis on this period, with seasons defined as September-October-November (SON), December-January-February (DJF), March-April-May (MAM), and June-July-August (JJA), respectively. To compare model, observational, and reanalysis data we label water years by the year in which August occurs. That is, September 1960 to August 1961 data is labelled as data for 1961 and September 2014 to August 2015 data is labelled as data for 2015 . We use conservative remapping to regrid all precipitation datasets to a common $0.6^{\circ}$ latitude by $0.8^{\circ}$ longitude resolution and analyze data from 1961 to 2015.

Atmospheric climate variables are extracted from the European Centre for Medium-Range Weather Forecasts (ECMWF) twentieth-century atmospheric reanalysis dataset (ERA-20C; Poli et al. 2013), ECMWF interim reanalysis dataset (ERA-Interim; Dee et al. 2011), and MOHCHadGEM3-GA6 model simulations presented above. The $2.0^{\circ} \times 2.0^{\circ}$ interpolated products from ERA-20C and ERAInterim are used. The reliability of ERA-Interim atmospheric fields to depict large-scale atmospheric features associated with extreme events (droughts) over Brazil (Pampuch et al. 2016) and elsewhere (Tedeschi and Collins 2017; South America) has been demonstrated. We compare 850$\mathrm{hPa}$ geopotential height and the vertical profile of vertical velocity fields from ERA-20C with those from ERA-Interim, for the period when the two datasets overlap (1981-2010), to assess the usefulness of ERA-20C atmospheric variables to depict large-scale atmospheric features over Brazil. The spatial patterns of the chosen variables from the two reanalyses are similar (Sect. 3.2). Having assessed ERA-20C, we then use it to examine the dynamics of drought events during the period 1961-2010, while ERA-Interim offers the opportunity to examine the 2013/2014 and 2014/2015 summer drought events.

The normalized precipitation anomaly in Sect. 3.1 is obtained from simple arithmetic mean. We compute the seasonal and annual precipitation anomaly at each grid for each year by subtracting the precipitation climatology during the reference period (1981-2010) from the precipitation data. The percentage normalized anomaly is then computed by dividing the anomaly by the climatological mean and multiplying by 100 . We perform this process separately for each 
season to avoid seasonality bias. The temporal evolution of precipitation departures over SSP is then obtained through cosine-latitude-weighted averaging. To characterize drought events over the region, we take the lowest 10 values of the series (relative to 1981-2010). These correspond to values less than or equal to the -1.0 standard deviation of the time series. For the simulations, we repeat the above procedure separately for each ensemble member from which we obtain the ensemble mean precipitation departure.

Using the above observed and simulated driest years as an index, we compute the seasonal composite anomaly, at $850-\mathrm{hPa}$ and $200-\mathrm{hPa}$, of geopotential height (Z850 and Z200), vertical velocity $(\omega)$, mean wind speed (V850 and $V 200)$, and zonal (u) and meridional winds (v) from the two reanalyses and model simulations. We compute the vertically integrated moisture flux convergence (VIMFC) from the monthly reanalysis. Seasonal anomalies are computed separately for each season relative to the 1981-2010 mean. The robustness of the composite anomaly of the large-scale fields associated with the drought events is assessed through statistical significance at the 95\% significance level using a Welch two-sample $t$-test. The VIMFC is represented as the sum of the moisture convergence by the divergent flow, moisture advection by the mean flow, and the surface quantity (residual) terms. According to previous studies (Banacos and Schultz 2005; Satyamurty et al. 2013; Seager and Henderson 2013; Pampuch et al. 2016), the VIMFC expression in vector form is given as:

$$
\begin{aligned}
\mathrm{VIMFC}= & -\frac{1}{g} \int_{P_{t}}^{P_{s}} \nabla \cdot\left(q V_{h}\right) d p=-\frac{1}{g} \int_{P_{t}}^{P_{s}} q \nabla \cdot V_{h} d p \\
& -\frac{1}{g} \int_{P_{t}}^{P_{s}} V_{h} \cdot \nabla q d p-\frac{1}{g} V_{h s} q_{s} \cdot \nabla p_{s}
\end{aligned}
$$

where $q$ is the specific humidity, $V_{h}$ is the horizontal mean flow at pressure $\mathrm{p}, \mathrm{g}$ is the acceleration due to gravity, $p_{\mathrm{s}}$ is the surface pressure, $V_{h s}$ is the horizontal mean flow at the surface, $q_{s}$ is the specific humidity at the surface, and $p_{\mathrm{t}}$ is the pressure at $100 \mathrm{hPa}$. The first, second, and third terms on the RHS of (Eq. 1) are the moisture convergence, moisture advection, and residual, respectively.

\section{Results and discussion}

\subsection{Climatology of precipitation: spatial and temporal distributions}

The spatial patterns of simulated and observed precipitation climatology (1961-2010) at annual and seasonal timescales, excluding JJA, are shown in Fig. 2. JJA is excluded from this analysis because it is the region's dry season. The model (Historical) reproduces the observed spatial patterns of mean precipitation at all timescales. At annual and seasonal timescales, the Amazon region is dominated by high precipitation, with low precipitation over northeast Brazil and the southern part of Southern America. During DJF, the peak precipitation season over most parts of Southern America, high precipitation extends southward and eastward covering most of Brazil, while northeastern Brazil, Chile, Argentina, and Uruguay receive low precipitation. The DJF precipitation pattern depicts the geographical location of the SACZ. During MAM when the Intertropical Convergence Zone (ITCZ) attains its southernmost position over northeast Brazil (Durand et al. 2005), most regions south of $10^{\circ} \mathrm{S}$ are dry. During this season, the east-west oriented maximum precipitation is located over the ITCZ region. This location is well simulated by the model. Comparison of the Historical precipitation pattern with that of Natural suggests both ensembles are similar (Fig. S1).

Despite the model's ability to capture the large-scale patterns of observed precipitation, there are biases in the precipitation amount. The simulations overestimate the precipitation over the Andes, which could be related to the model's inability to resolve topography; consistent with most models (Abadi et al. 2017). The percentage of precipitation bias over the State of São Paulo and at the continental scale at both the annual and seasonal timescales is presented in Table 1. At all seasons, the model overestimates the intensity of precipitation over SSP with values that range from about $6-52 \%$ and over the continent by as much as about $18-32 \%$. The results in Table 1 indicate that precipitation amounts from Historical and Natural simulations are similar.

The temporal evolution of the observed normalized annual precipitation anomaly averaged over SSP during the period 1961-2015 is characterized by interannual variability of about $10 \%$ (Fig. 3a). There is a small positive trend in the normalized precipitation anomaly $\left(1.3 \% \mathrm{decade}^{-1}\right)$, consistent with previous studies (Vera and Diaz 2015; de Barros Soares et al. 2017). The 1960s, late-1970s, mid-1980s to early-1990s, and early-2000s are dominated by below-average precipitation, with the largest mean precipitation decrease occurring from the mid1980s to early-1990s ( $-5.4 \%)$. The region also experienced above-average precipitation during 1993-1999 and 2008-2012. However, from 2009, a decline in normalized precipitation anomaly is observed. Ranked in order of dryness, the years below 1.0-standard deviation are 1969, 1981, 1964, 2000, 1968, 1986, 1963, 1975, 1978, and 1988. These drought episodes include El Niño, La Niña, 

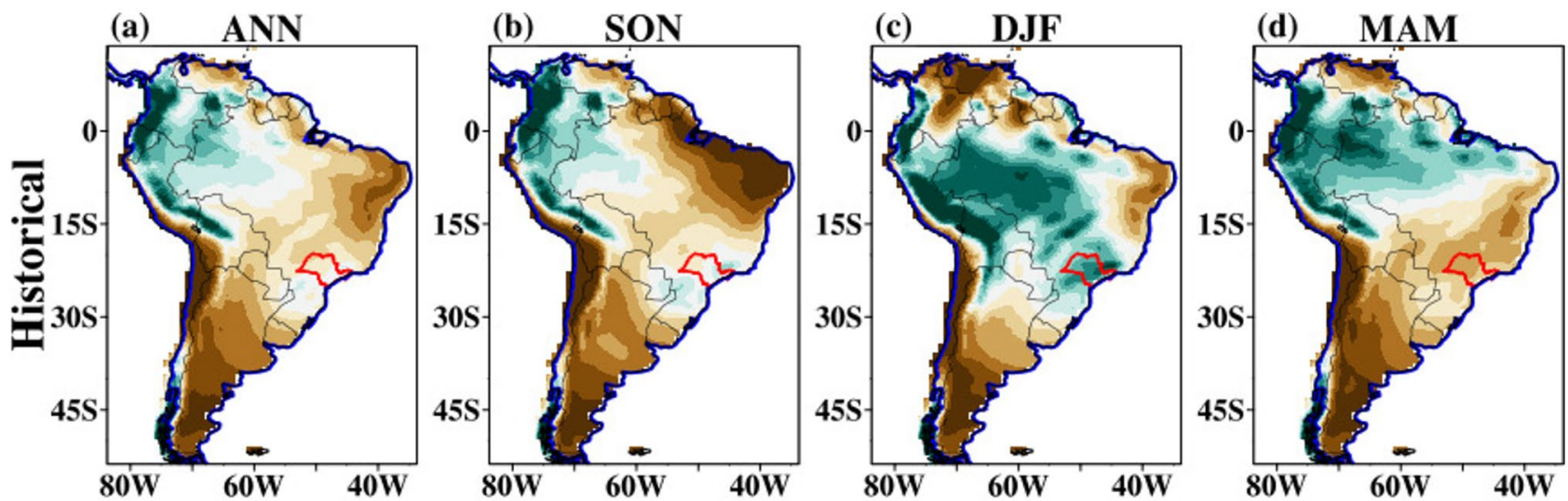

(e)
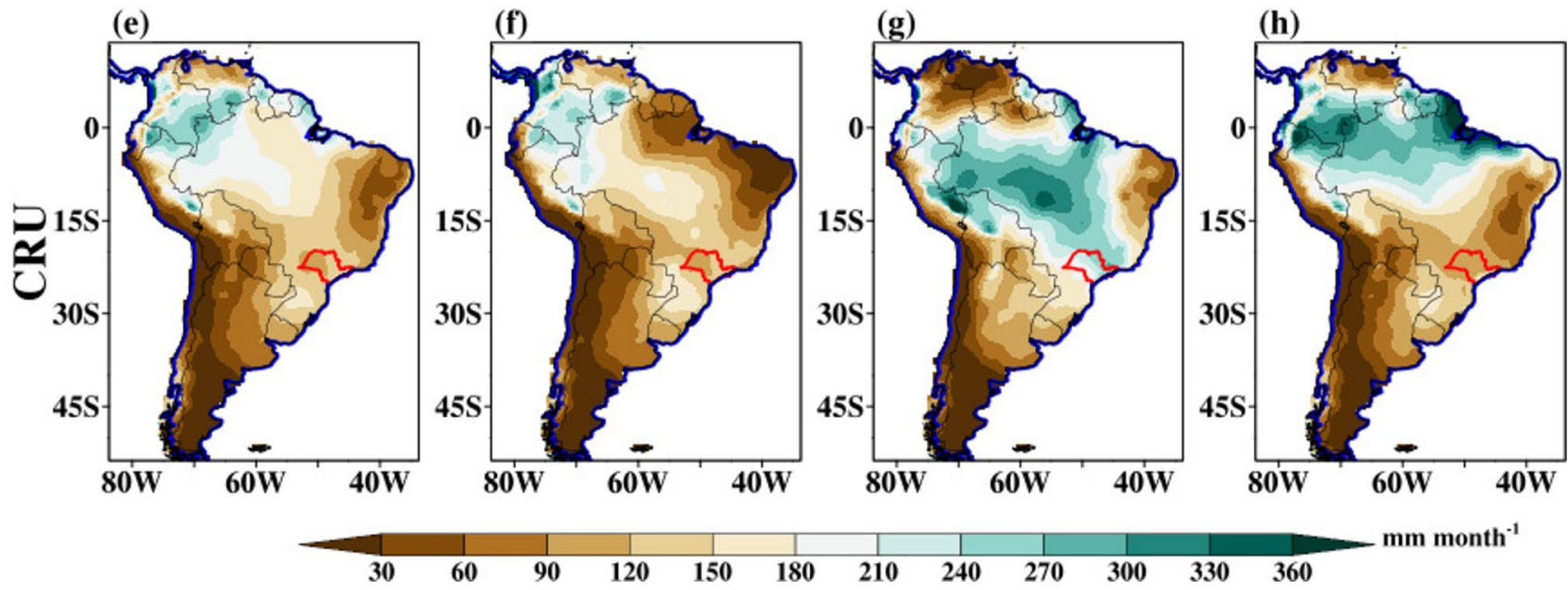

Fig. 2 Annual and seasonal mean precipitation from Historical simulation (a, b, c, and d) and CRU (e, f, g, and h) for 1961-2010. The solid blue, black, and red lines indicate the coastline, Brazil, and State of São Paulo, respectively

Table 1 Percentage bias of model precipitation over the State of São Paulo and the Southern America continent at the annual and seasonal timescales

\begin{tabular}{|c|c|c|c|c|c|c|c|c|}
\hline \multirow[t]{2}{*}{ Dataset } & \multicolumn{4}{|c|}{ State of Sao Paulo } & \multicolumn{4}{|c|}{ South America } \\
\hline & Ann & SON & DJF & MAM & Ann & SON & DJF & MAM \\
\hline HadGEM3_Hist & 35 & 52 & 26 & 6 & 25 & 32 & 25 & 18 \\
\hline HadGEM3_HistNat & 33 & 50 & 24 & 6 & 25 & 32 & 26 & 18 \\
\hline
\end{tabular}

The bias is relative to observations and neutral years, suggesting that different mechanisms produce droughts over SSP or little relationship with El Nino. The year 2014 (hereafter, 2014), included among the years below 0.5 -standard deviation, is noted for its historical severity in terms of hydrological drought and socio-economic impacts due to water demand in the SSP (Otto et al. 2015), but as a meteorological drought, it is ranked 14th within our analysis period. The 2014 drought episode is associated with neutral ENSO conditions $\left(\mathrm{NOAA}^{1}\right)$. Further analysis of this episode is presented in

\footnotetext{
${ }^{1}$ https://ggweather.com/enso/oni.htm.
}

Section 3.4 to enhance our understanding of the seasonality and physical mechanisms of this high-impact drought. The pattern of the mean of simulated normalized annual precipitation anomalies is similar to that of the observed with a correlation between the ensemble mean and observation of 0.34 . However, the models overestimate the interannual variability. Also, there is no considerable difference between the ensemble mean of Historical and Natural simulations (Fig. not shown).

The interannual evolution of observed and simulated normalized precipitation anomalies on seasonal timescales is presented in Fig. 3b-d. There is a considerable year-to-year interannual variability of observed normalized precipitation 

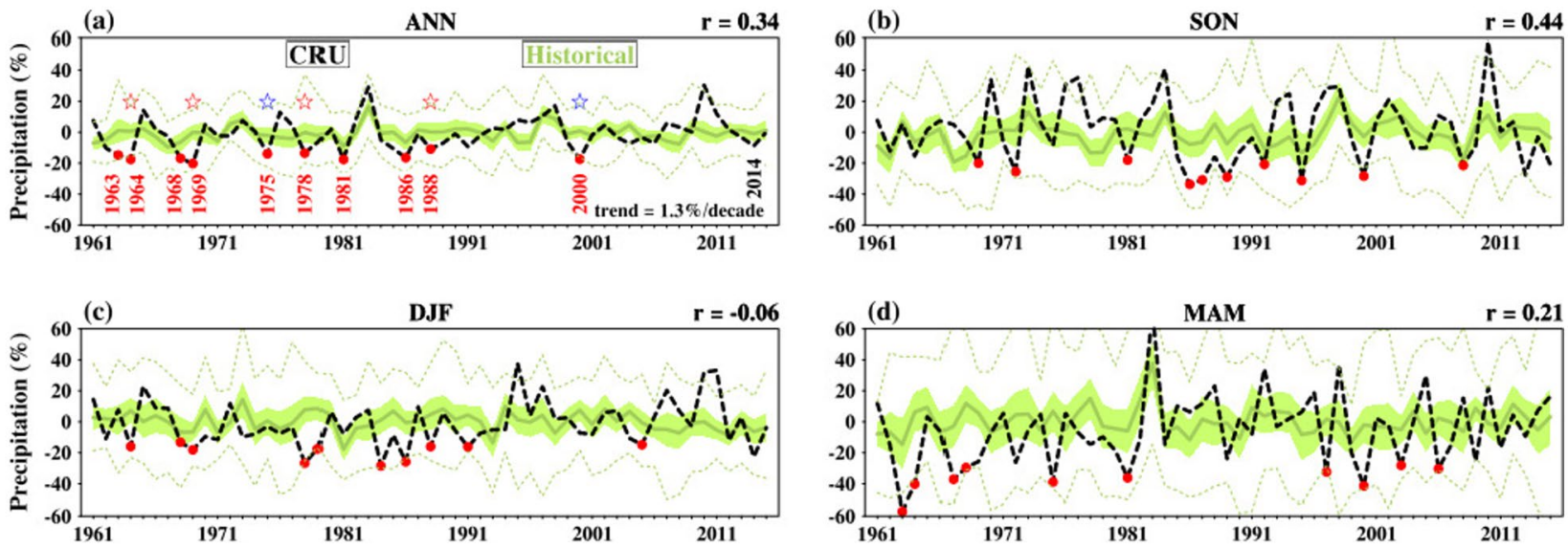

Fig. 3 Annual (a) and seasonal (b-d) observed and simulated interannual variability of normalized spatially averaged precipitation anomalies relative to $1981-2010$ over SSP $\left(20^{\circ}-25^{\circ} \mathrm{S} ; 53^{\circ}-45^{\circ} \mathrm{W}\right)$ for 1961-2015 period. The observed precipitation anomaly (dashed black line) is indicated with red dots indicating the 10 driest years

anomalies at all seasons, except for DJF where most of the values are contained within the $-20-20 \%$ precipitation threshold band. Consistent with the normalized annual precipitation anomaly in Fig. 3a, the patterns of observed normalized seasonal precipitation anomalies show peaks in 1984 (SON) and 1983 (MAM), after which a decrease in precipitation is observed. However, these peaks are not discernible in DJF (Fig. 3c). Also indicated in Fig. 3 are the 10 dry years (red dots), and it is interesting to note that the region has experienced dry summers (DJF) during both weak La Niña and neutral ENSO events. The Historical simulation shows the ability to capture the interannual variability of the observed precipitation, but with differences. For example, the model reproduces the magnitude of the peak precipitation in 1973 (SON), 1993 (MAM), amongst others, but some of the peaks are not well reproduced. With these, the correlation coefficient between observed and ensemble mean precipitation during SON, DJF, and MAM are 0.44 (significant), -0.06 , and 0.21 , respectively.

The ability of the HadGEM3-GA6 model to simulate meteorological drought is examined and compared with observations. The composite of observed normalized seasonal precipitation anomaly during dry periods, indicated by red dots in Fig. 3b-d, shows precipitation deficits over SSP and other parts of South America (Fig. 4d-f). However, the deficit is significant over SSP. During SON and MAM, wet precipitation anomalies are observed over parts of the Amazonas, Roraima, Pará States, and northeastern Brazil. However, in DJF, there is a local precipitation maximum over northeastern Brazil. The southeast-northwest oriented normalized precipitation deficit pattern suggests a weaker than normal SACZ.

during the period. The red and blue stars in panel (a) indicate the El Nino and La Nina years. The solid olive-green line shows the Historical precipitation anomalies, the olive-green envelope represents the model 5th-95th percentile range, while the dashed lines indicate the model ensemble spread (min and max)

In SON, the Historical model ensemble (Fig. 4a) overestimate the wet precipitation anomaly over the ITCZ, while underestimating and missing the structure of the precipitation maximum along the border between Bolivia and Argentina. The pattern correlation of Historical with observation is 0.5. This correlation is moderate because the model ensemble captured the dry precipitation anomaly well. In DJF, the ensemble simulates poorly the structure and intensity of normalized precipitation anomaly over a large part of South America (Fig. 4b). Unlike in observations, the simulation is dryer to the north of SSP and wetter over Amazonia. This different signal leads to a poor pattern correlation value of 0.02. As in SON, the ensemble is dryer around SSP and wetter in the northern region of Brazil during MAM (Fig. 4c).

\subsection{Climatological pattern of atmospheric variables in ERA-20C and ERA-Interim}

To verify if ERA-20C is reliable, the spatial patterns of the vertical profile of vertical velocity, 500-hPa geopotential height, and the 850-hPa MFC are compared with ERAInterim for 1981-2010. Seasonal vertical velocities from the two reanalyses are similar, although with slight differences in magnitude (Fig. 5). The intensity of vertical velocity is about $1 \mathrm{~Pa} \mathrm{~s}^{-1}$ higher in ERA-20C than ERA-Interim in SON, while it is about the same in DJF and MAM. The difference between the two reanalyses is that the spatial spread of the ascending motion is slightly wider in ERA-20C than in ERA-Interim. The vector wind is also slightly stronger in ERA-20C than in ERA-Interim, with the largest and widespread wind vectors in the DJF season.

ERA-20C and ERA-Interim seasonal-mean $850-\mathrm{hPa}$ geopotential height are similar (Fig. 6). Heights range from 
Fig. 4 Composites of normalized precipitation anomaly for dry episodes over State of São Paulo (SSP; red outline) during the period 1961-2010 from Historical (a, b, and c) simulations, and CRU observations $(\mathbf{d}, \mathbf{e}$, and $\mathbf{f})$. The value at the bottom right corner shows the percentage change in precipitation anomaly averaged over SSP. The hashed areas in the top row indicate where the model is statistically significantly different from CRU at the $95 \%$ level
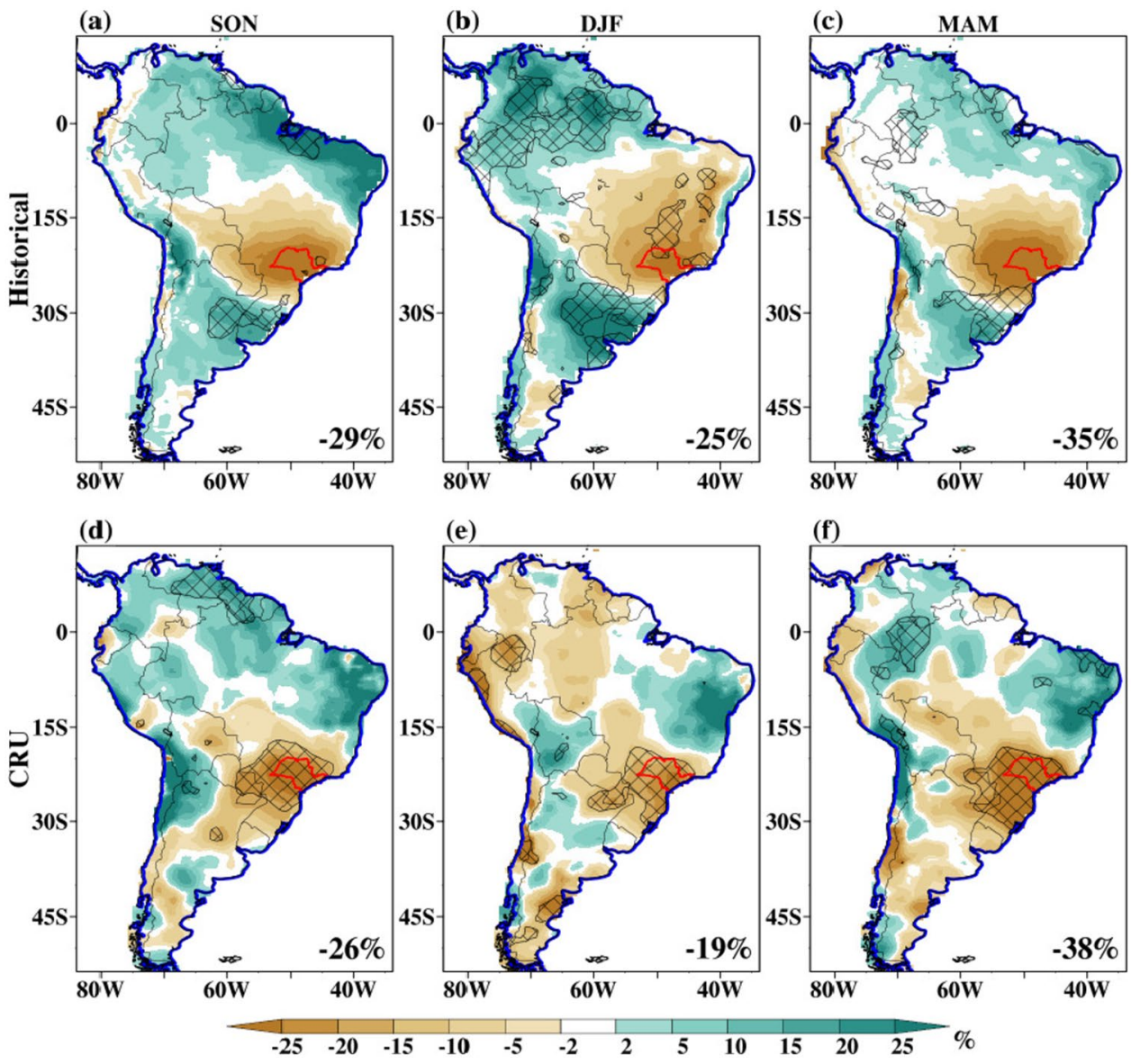

1100 to $1500 \mathrm{~m}$ and the two reanalyses reasonably agree on the position of the climatological $1500 \mathrm{~m}$ contour. There is also a strong agreement between the two reanalyses concerning the low-level wind vectors. The similarities in the patterns and magnitude of the above atmospheric variables from ERA-20C and ERA-Interim show ERA-20C is reliable over the study region.

\subsection{Simulated and observed mechanisms for summer drought over SSP}

How well HadGEM3-GA6 can capture the dynamical features associated with austral summer droughts over SSP is examined by comparing the available simulated atmospheric variables with those from ERA-20C. We focus on DJF (austral summer) because of the importance of this season's precipitation to the mean climate over the region. Also more recently, the region has experienced one of its worst water deficits during this season (e.g., Coelho et al. 2016a, b).

\subsubsection{Atmospheric moisture content}

Here we examine the composite of ERA-20C atmospheric moisture budget anomalies during austral summer drought events for 1961-2010. Figure 7 shows the spatial distribution of vertically integrated moisture flux convergence (VIMFC) and its components (Eq. (1); convergence, advection, and residual terms). During the drought events, VIMFC (Fig. 7a) exhibits a northwest-southeast oriented moisture deficit centred over SSP and increasing to the north. Comparing Fig. 7a and Fig. 7b, there is a strong similarity, near SSP, between the spatial patterns of VIMFC and the convergence term with a pattern correlation value of 0.78 . These features are also associated with statistically significant upper-level convergence along a northwest-southeast axis through SSP (Fig. 8b). In response, the low-level atmosphere around SSP is characterized by weaker divergence anomalies (Fig. 8a). Looking at the last two terms in Eq. 1, that is, the contributions from both the advection (Fig. 7c) and the residual (Fig. 7d) to the VIMFC, it is noted that only the advection 

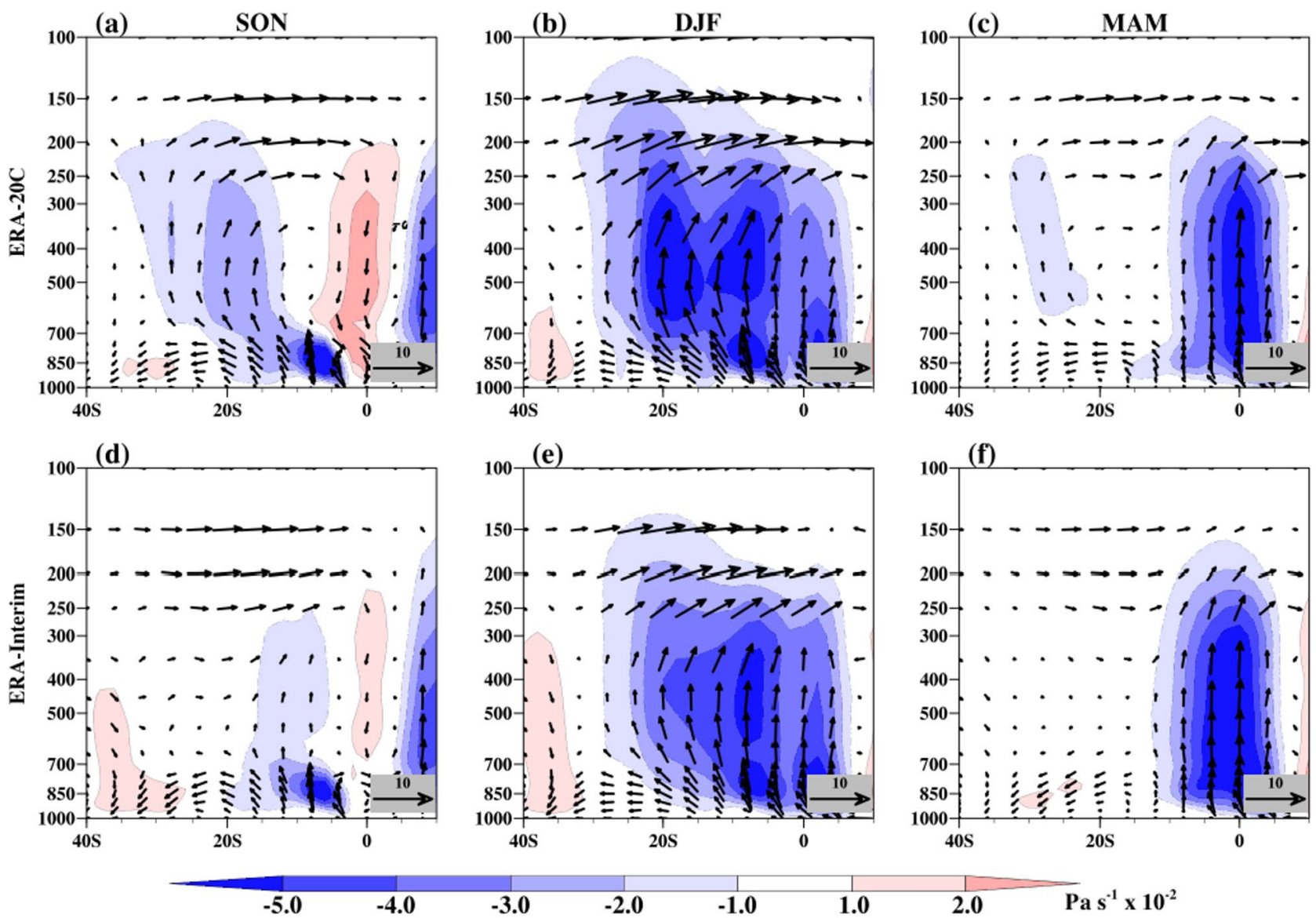

Fig. 5 Latitude-height plot of seasonal mean vertical velocity (shaded) overlaid with meridional wind component and vertical velocity (vector) averaged across the longitude band of SSP $\left(40^{\circ}-56^{\circ} \mathrm{W}\right)$ for $1981-2010$. The panels are for ERA-20C (a, b, and c) and ERA-Interim (d, e, and f)
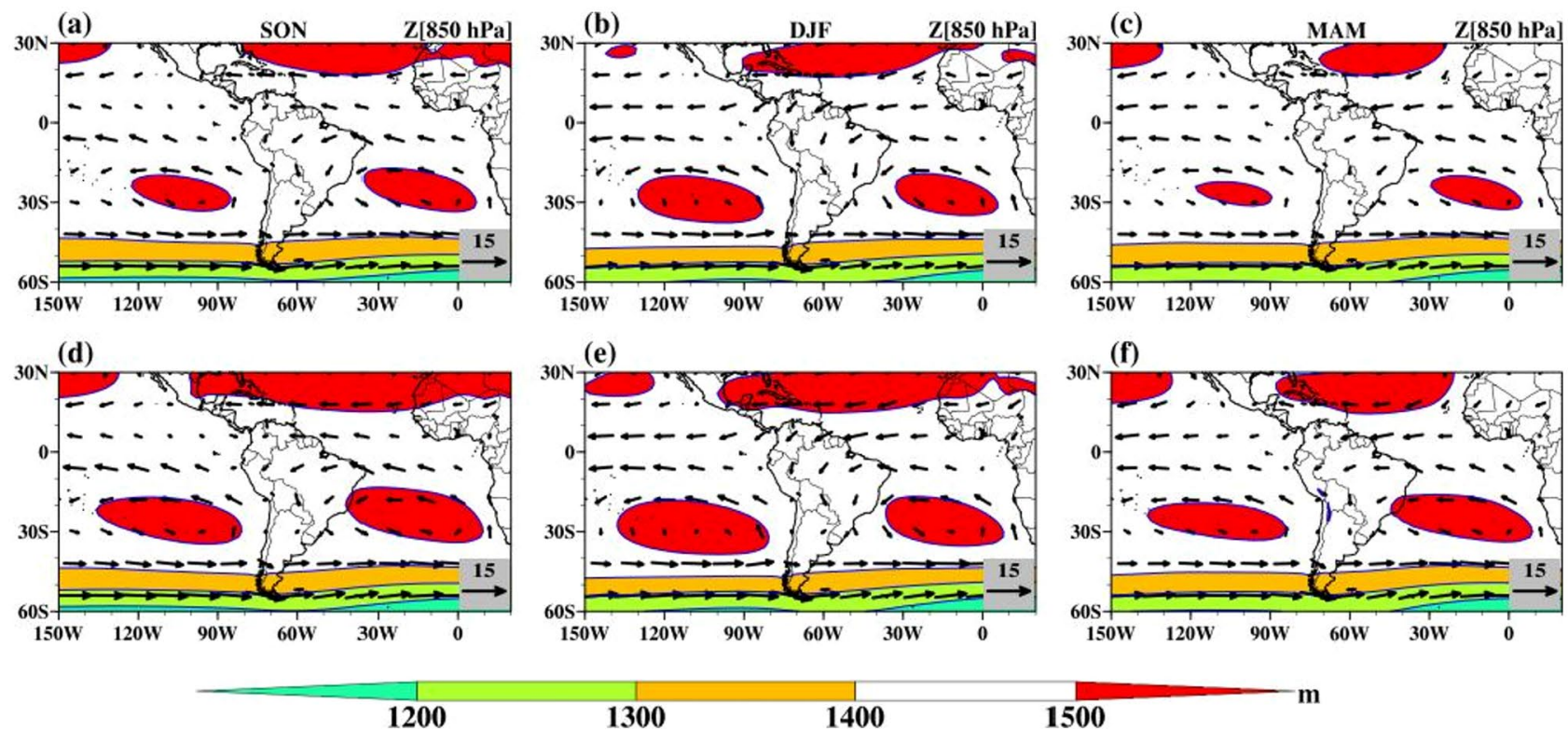

Fig. 6 Seasonal mean geopotential height overlaid with horizontal winds (vectors; $\mathrm{m} / \mathrm{s}$ ) at $850 \mathrm{hPa}$ for ERA-20C (a, b, and c) and ERA-Interim (d, e, and f) during the period 1981-2010. Wind arrow scale is shown at the bottom right hand plot 
Fig. 7 ERA-20C DJF a vertically integrated moisture flux convergence, VIMFC (shading; $\mathrm{kg} \mathrm{m}^{-2} \mathrm{~s}^{-1} \times 10^{-10}$ ) anomalies decomposed into $\mathbf{b}$ convergence by anomalous flow (VIMFCc), c advection by mean flow (VIMFCa), and c residual. Only values which are significantly different, at the $95 \%$ level, from the other years are plotted. Positive and negative anomalies denote increased and decreased moisture convergence, respectively. Panels $(\mathbf{a}-\mathbf{c})$ are overlaid with their respective moisture flux transports (grey vector arrows) with the statistical significance, at the $95 \%$ level, vectors indicated with solid black arrows
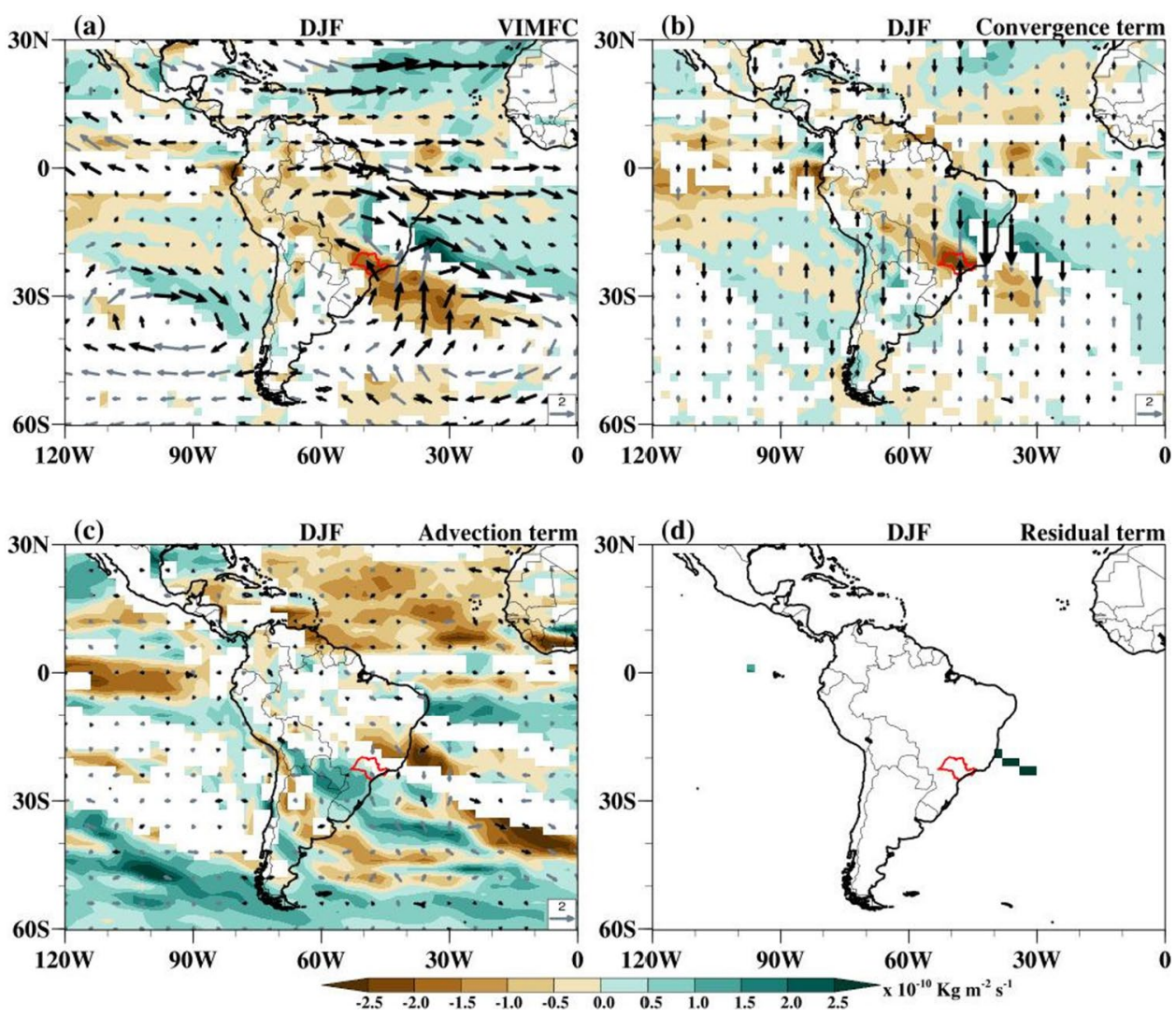

Fig. 8 ERA-20C DJF a 850and b 200-hPa levels divergence anomalies, (contours; $\mathrm{s}^{-1} \times 10^{-6}$ ) overlaid with divergent wind vector (grey arrows) anomalies. Statistically significant vectors are indicated with solid black arrows. The positive (negative) values indicate anomalous divergence (convergence), respectively. Only statistically significant values at the $95 \%$ are plotted

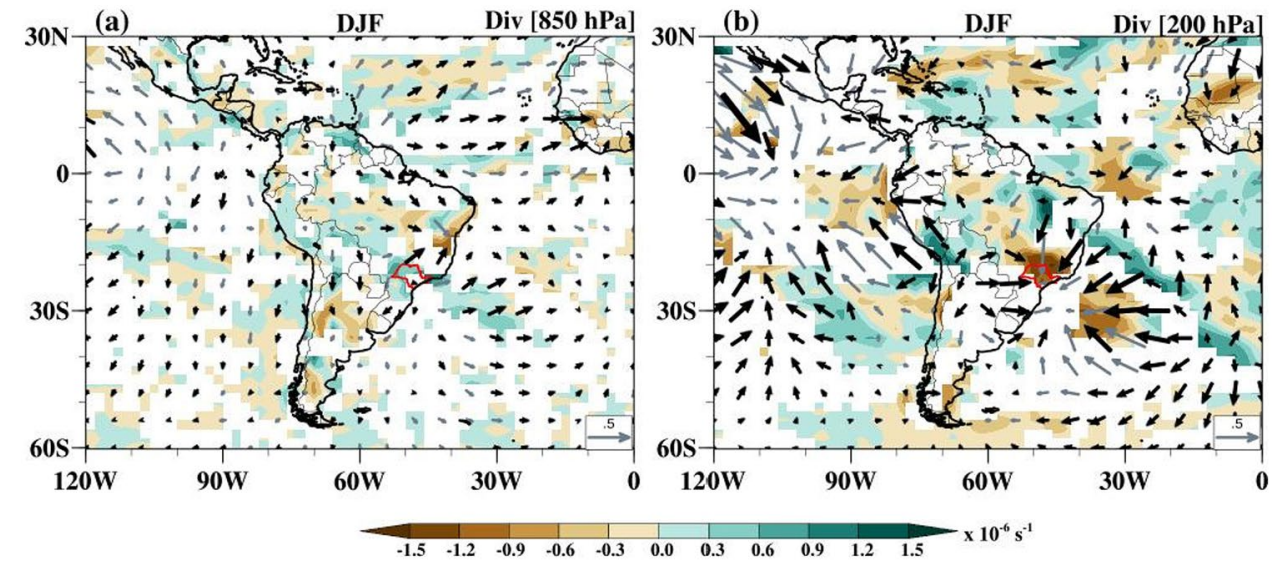

term contributes to the VIMFC. The magnitude over SSP is weak, with values that range -0.5 to $0.5 \times 10^{-6} \mathrm{~kg} \mathrm{~m}^{-2} \mathrm{~s}^{-1}$. The residual term is also important for the VIMFC, but the contribution here is not statistically significant. Taken together, changes in VIMFC are dominated by changes in convergence with a contribution from the advection term confirming that reduced moisture convergence is the main driver of droughts, while changes in the advection term act to advect moisture away from SSP during the period of study. Abadi et al. (2017) stated that strong moisture divergence represents regions with evaporation higher than precipitation; that is atmospheric moisture sources. The coincidence of the reduced VIMFC position with the region of reduced precipitation as indicated in Fig. 4d indicates that droughts occur as a result of a lack of atmospheric moisture over SSP. Thus, we can infer that drought over SSP is due to more moisture transport to the north than normal and the SACZ not moving as far south as normal. 
Fig. 9 Composite (top) anomalous 850- and (bottom) 200-hPa geopotential height (shading; $\mathrm{m}$ ) and zonal and meridional wind components (vectors; $\mathrm{m} \mathrm{s}^{-1}$ ) anomalies during DJF drought over SSP during the period 1961-2010 from ERA-20C and Historical simulations. Hatched areas in $\mathrm{b}$ and $\mathrm{d}$ indicate where model height statistically significance than reanalysis height. The dashed blue and red contour lines in $\mathrm{c}$ and $\mathrm{d}$ indicate the 1.5 and $-1.5 \mathrm{~m} \mathrm{~s}^{-1}$ wind speed respectively. Red symbol $\mathrm{C}$ indicates anomalous cyclonic circulation and blue symbol $\mathrm{H}$ indicates anomalous anticyclonic circulation centers
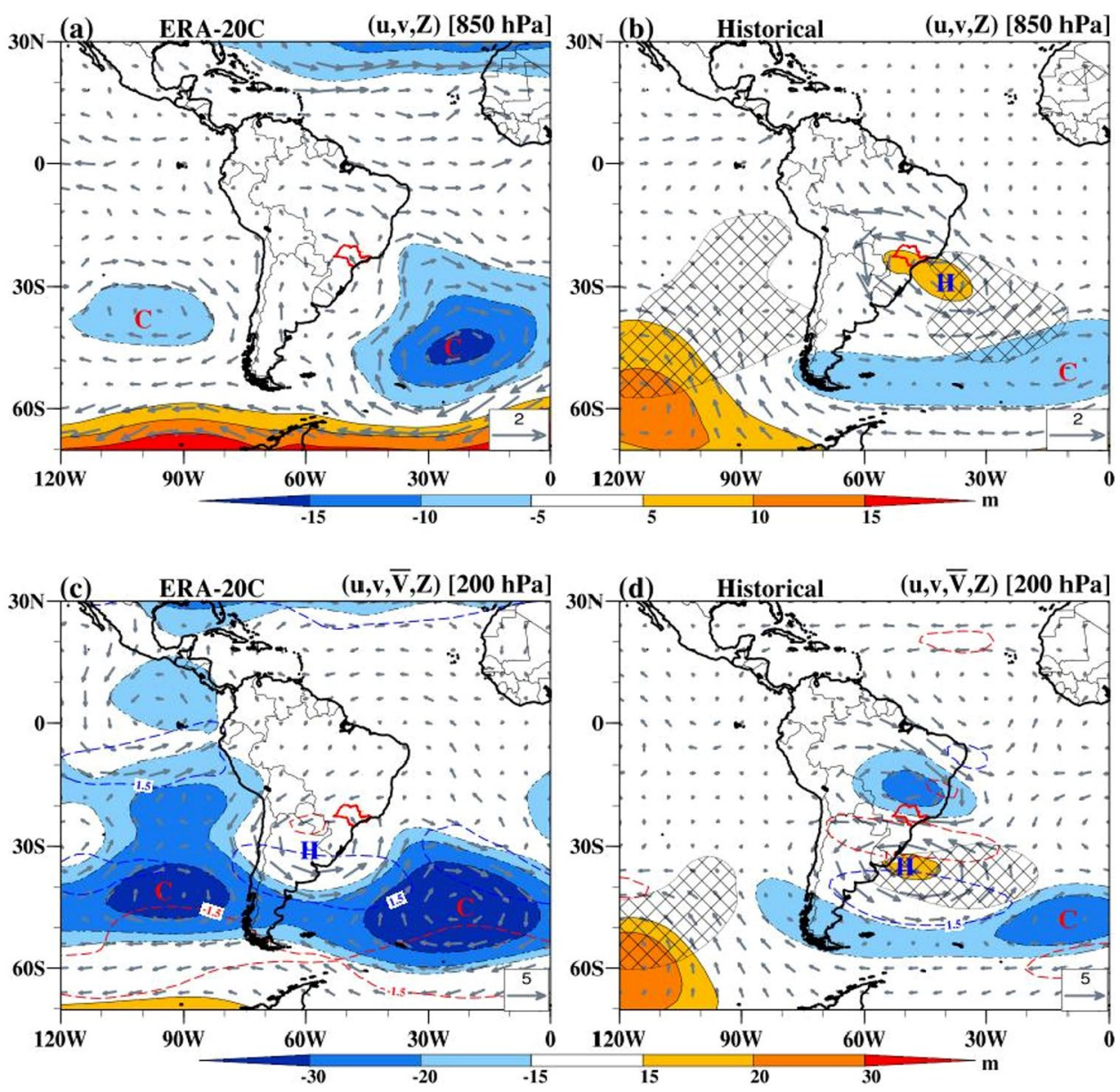

\subsubsection{Atmospheric circulation changes}

During droughts, ERA-20C shows that $850 \mathrm{hPa}$ winds are close to normal conditions as indicated by weak values that range from -0.3 to $0.3 \mathrm{~m} \mathrm{~s}^{-1}$ over South America. However, some parts of northeastern Brazil and northern SSP show stronger negative anomalies with values between $-0.6 \mathrm{~m} \mathrm{~s}^{-1}$ and $-0.3 \mathrm{~m} \mathrm{~s}^{-1}$, consistent with the strong wind vectors (contour not shown). The Amazon basin stores moisture from the tropical North Atlantic Ocean via the enhanced northeast trade winds (Marengo 1992). However, during DJF in SSP drought (Fig. 9a), the Amazon is characterized by very weak circulation consistent with weak VIMFC (Fig. 7). Also, the circulation over northeastern Brazil is dominated by a strong westerly wind, advecting moisture away from SSP. This, in turn, explains the changes in moisture flux seen in Fig. 7a. The $850 \mathrm{hPa}$ wind anomalies are characterized by the presence of a weak anticyclonic circulation south of SSP and anomalous cyclonic circulations over the subtropical South Atlantic and Pacific Oceans. The westerly trade winds of the northern branch of this cyclonic circulation merge with the westerly flow from northeastern Brazil to move the eastward moisture transport away from the continent. The weak anticyclonic circulation is associated with a weak positive geopotential height anomaly, which is in agreement with the low-level divergence anomaly (Fig. 8a); an indication of an unconducive environment for convection development over the region. From the analysis in Fig. 9a, we suggest that the failure of the northeast trade winds and the South America low-level jet that supplies moisture to the continental region through the Amazon, in conjunction with SACZ that does not move south as it normally does, explains the reduced precipitation leading to droughts over SSP.

The pattern of wind anomaly (as indicated by the vector direction) from the ensemble mean of Historical simulations is opposite to the observed pattern over northeastern Brazil (Fig. 9b). However, it is similar but more widespread and stronger to the west of SSP. This is associated with a much larger height anomaly and associated anticyclonic circulation than the reanalysis. This strong contrast might explain the higher intensity of simulated negative precipitation anomaly (Fig. 4b, e) because the model has very strong subsidence.

Previous studies have highlighted the importance of the anticyclonic circulation to the South American monsoon system (e.g., Ramírez et al. 1999; Garreaud et al. 2003; 
Fig. 10 Latitude-height plot of anomalous vertical velocity (shaded) overlaid with vectors of anomalous meridional wind component and vertical velocity averaged across the longitude band of SSP $\left(40^{\circ}-56^{\circ} \mathrm{W}\right)$ for DJF drought events during the period 1961-2010 from a ERA$20 \mathrm{C}$ and b Historical simulations. The green dotted areas show statistically significance at the $95 \%$ confidence level

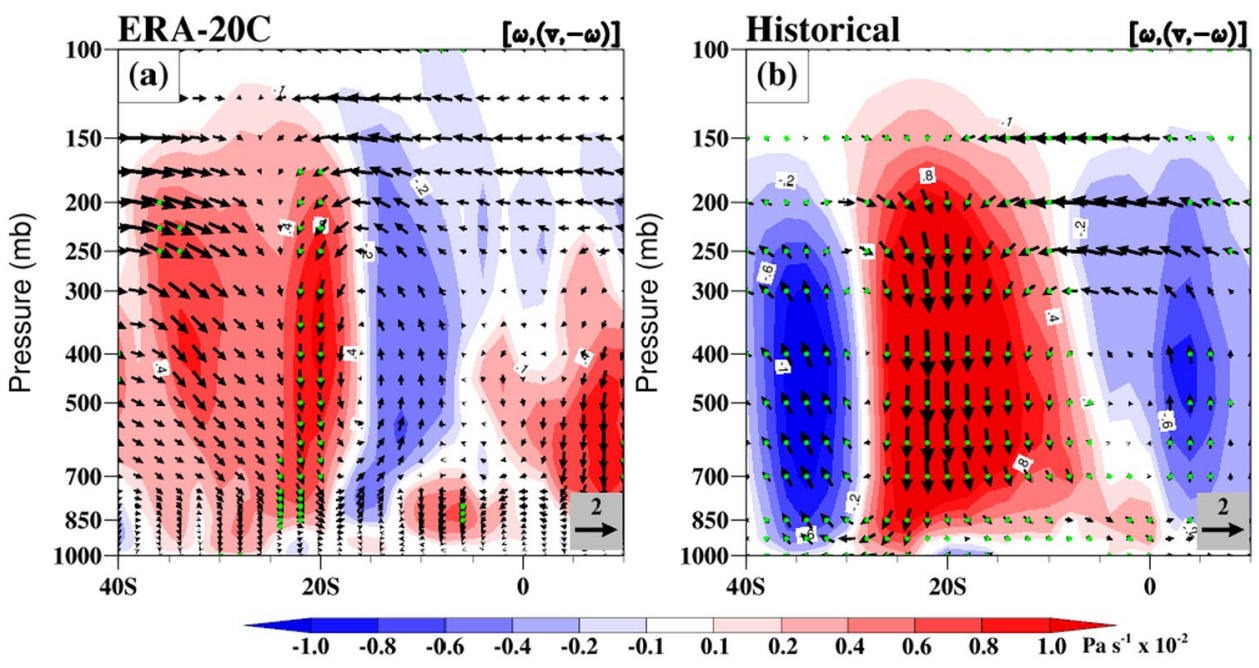

Ferreira et al. 2004; Marengo et al. 2012; Insel et al. 2013; Abadi et al. 2017). These studies indicated that during DJF, the monsoon system is characterized by a well-established upper-level anticyclonic circulation over Bolivia (the Bolivian High; BH) in conjunction with a semi-permanent low pressure system (the Chaco thermal Low) over northern Argentina, strong lower-tropospheric convergence, and upper-level divergence. During this season, the $\mathrm{BH}$ can modify the precipitation over the region through the development of deep convection. The focus of this section is to examine the location and the intensity of the $\mathrm{BH}$ associated with drought events over SSP. The $200 \mathrm{hPa}$ positive wind anomaly (dashed blue contours), in ERA-20C, shows a zonally elongated structure along $30^{\circ} \mathrm{S}-45^{\circ} \mathrm{S}$ with a significant core over central Argentina (Fig. 9c). Southward of this positive wind anomaly is a band of negative wind anomalies (dashed red contours) of about the same magnitude. These wind anomaly patterns are associated with strong upperlevel westerly and easterly flows. The exit region of the westerly flow over central Argentina converges with that of the easterly flow over subtropical Southwest Atlantic along $30^{\circ} \mathrm{S}-42^{\circ} \mathrm{S}, 35^{\circ} \mathrm{W}-45^{\circ} \mathrm{W}$ to induce an upper-level convergence (Fig. 8b). While the Bolivian high is not apparent in our analysis, we find anomalous anticyclonic $(\mathrm{H})$ circulation over northern Argentina flanked in the southern part by two oceanic cyclonic $(C)$ circulations. It thus appears that the strong circulation to the south of this high (weak positive height) is driven by the anomalous negative height (cyclonic circulation).

There are differences in the position of anomalous high between the composites based on ERA-20C and model simulations, but there are some similar features (Fig. 9d). The model captures the observed anomalous high but it is displaced south-eastward with its center over Uruguay and the oceanic region. The co-location of the model significant anomalous high with the wind field coupled with upper-level convergence and a pair of intense cyclonic circulations over the subtropical Southwestern Atlantic Ocean and the southeast Pacific Ocean suggests that this high pressure system plays an important role in inducing droughts over SSP by blocking the SACZ to move southward. Thus, we can infer that these interactions promote less moisture transport, subsidence motion, and strong surface divergence that inhibits convection, and can explain the precipitation deficit over SSP.

The model shows the ability to simulate the upper-level anticyclonic circulation (Fig. 9d). However, the ensemble mean of Historical simulations places the core of the high pressure system over the ocean. Similarly, the intensity of the simulated anticyclonic circulation is stronger than that of observations. The moisture-advection easterlies to the northern flank of the anticyclonic circulation are stronger than in observations; this explains the simulated positive precipitation anomaly over that location (Fig. $4 \mathrm{~b} ; 30^{\circ} \mathrm{S}, 60^{\circ} \mathrm{W}$ ).

\subsubsection{Vertical profile of omega vertical velocity}

Droughts over southeastern Brazil can be explained by a regional Hadley (meridional) circulation, where subsidence (consistent with weakened upper-level anticyclonic circulation and southward located wind field anomaly; Fig. 9c) results in less cloud formation and reduced precipitation (Coelho et al. 2016b). The analysis of the vertical velocity can thus offer an understanding of the drivers of SSP droughts. The composite analysis of observed vertical velocity averaged between $56^{\circ} \mathrm{W}$ and $40^{\circ} \mathrm{W}$ (the longitudinal band of SSP) in DJF for drought events during 1961-2010 shows subsidence (positive anomalies) between $15^{\circ} \mathrm{S}$ and $30^{\circ} \mathrm{S}$, with the core over SSP at $19^{\circ} \mathrm{S}-24^{\circ} \mathrm{S}$ (Fig. 10a). This anomalous subsidence is associated with reduced precipitation (Fig. 4e). Ascent to the north, between $0^{\circ}$ and $13^{\circ} \mathrm{S}$, 
Fig. 11 Latitude-height plot of anomalous vertical velocity (shaded) overlaid with vectors of anomalous meridional wind component and vertical velocity averaged across the longitude band of SSP $\left(40^{\circ}-56^{\circ} \mathrm{W}\right)$ for DJF drought events during the period 2013/14 and 2014/15 from a ERA-Interim and b Historical simulations. The green dotted areas show statistical significance at the $95 \%$ confidence level for the vertical velocity

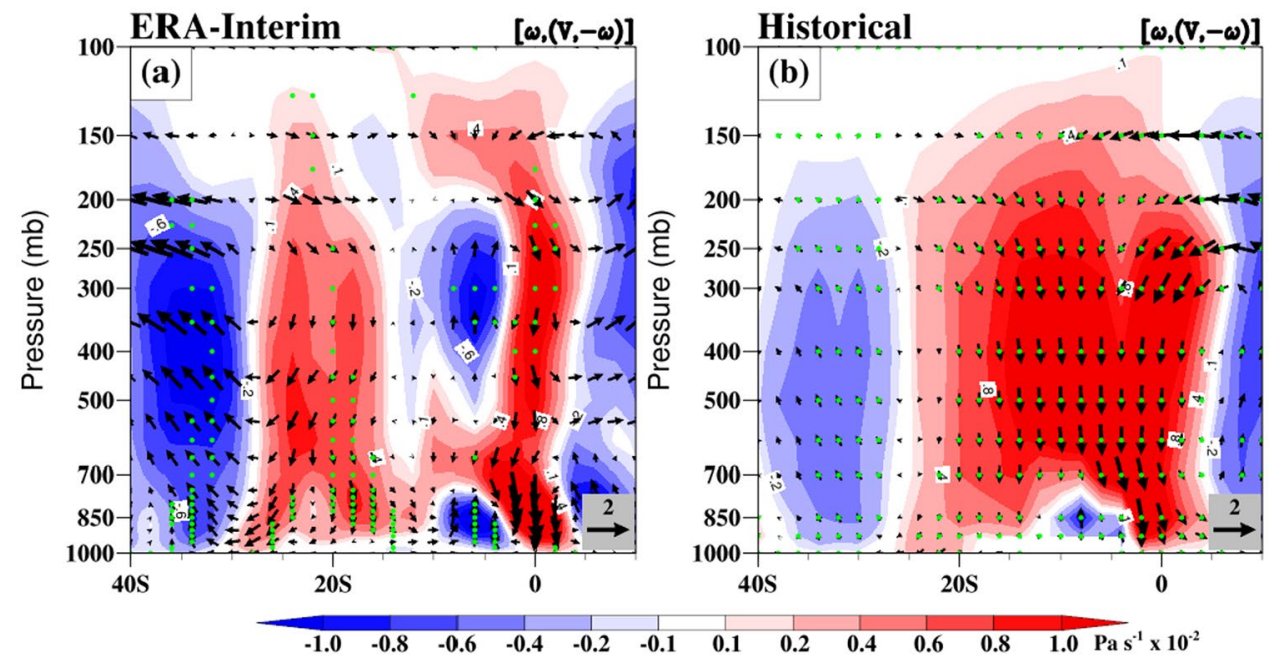

indicates favorable conditions for cloud formation and precipitation, consistent with anomalous positive precipitation over northeastern Brazil (Fig. 4e). This result is consistent with Coelho et al. (2016b).

The model ensemble reproduces the vertical structure of the vertical velocity anomalies averaged over SSP, although with substantial biases (Fig. 10b). The patterns of the vertical velocity anomalies from Historical and Natural simulations are fairly similar, such that the difference between their intensities is very small, with values between $-0.2 \times 10^{-2} \mathrm{~Pa} \mathrm{~s}^{-1}$ and $0.2 \times 10^{-2} \mathrm{~Pa} \mathrm{~s}^{-1}$ (supporting Fig. $\mathrm{S} 1)$. Compared with observation, the model has too stronger subsidence (greater than $1.2 \times 10^{-2} \mathrm{~Pa} \mathrm{~s}^{-1}$ over the SSP) over a wider domain from about $6^{\circ} \mathrm{S}-28^{\circ} \mathrm{S}$, missing the location of the ascent centered around $10^{\circ} \mathrm{S}$ in the reanalysis. The model also has ascent centered at $30^{\circ} \mathrm{S}$ that is not in the reanalysis. This statistically significant intense subsidence anomaly is associated with the lower atmospheric level anticyclonic circulation over SSP, suggesting that the simulated droughts are related to excess stability. This feature is also associated with the simulated precipitation deficits (Fig. 4b), suggesting that HadGEM3-GA6 simulated precipitation anomalies associated with drought events.

\subsection{Mechanism of 2013/2014 and 2014/2015 summer droughts over the State of São Paulo}

To shed light on the atmospheric driver of recent drought events over SSP we compare the mechanisms of these 2013/2014 and 2014/2015 austral summer droughts with other droughts considered earlier. For this analysis, we use the ERA-Interim reanalysis because of the availability of data beyond 2010 and its greater reliability.

There is consistency between the structures of the vertical velocity anomalies during 1415SD (Fig. 11a) and other drought events during the period 1961-2010 (Fig. 10a).
There is descent between $15^{\circ} \mathrm{S}$ and $30^{\circ} \mathrm{S}$ with the maxima over SSP $\left(20-30^{\circ} \mathrm{S}\right)$ and the equator $\left(5^{\circ} \mathrm{S}-5^{\circ} \mathrm{N}\right)$ (Fig. 11a). The subsidence over the equator is associated with a weakening of the ITCZ/trade winds (Durand et al. 2005). These descents are separated by intense ascent over the northern and southern parts of SSP. This alternating pattern of the vertical velocity supports the development of upper-level convergence and low-level divergence. The 1415SD is in agreement with the anomalous positive vertical velocity over SSP. Thus, the descent motion acts to inhibit convection as evident in the precipitation deficits over SSP. This result is consistent with the result of Coelho et al. (2016b; their Fig. 6c) that concluded that the vertical velocity anomalies characterize the local Hadley cell circulation, connecting the circulation of the neighboring Atlantic Ocean with that of southeastern Brazil.

The model (Historical simulations) shows the ability to simulate the spatial pattern of the vertical velocity anomaly during the 1415SD; however, the simulated magnitude is slightly weak over the SSP domain (Fig. 11b). A similar feature is depicted by the simulated vertical velocity in Fig. 11b and Fig. 10b, with the exception that the subsidence motion during 1415SD is broad and displaced further north to latitude $5^{\circ} \mathrm{N}$. The observed and simulated vertical velocity anomalies during 1415SD are consistent in the sense that they both show the shallow ascent located between $0^{\circ}$ and $10^{\circ} \mathrm{S}$. Also, the structure of the intense ascent north of $0^{\circ}$ and south of $30^{\circ} \mathrm{S}$ is simulated by the model. The main difference is that the model misses the mid-tropospheric ascent. Despite the slight differences in the structures and magnitudes of the descending motion during 1415SD and the other driest summers, we can conclude that the mechanisms leading to 2013/2014 and 2014/2015 DJF droughts over SSP are consistent with other drought events over the region during the period of study. 


\section{Conclusions}

During the austral summer of 2013/2014 and 2014/2015, the State of São Paulo, Brazil (SSP) was impacted by intense drought. This event led to several impacts on freshwater availability for human consumption, energy production, and other socio-economic activities. The magnitude of the impact of this drought caught government attention to respond to human water needs by extracting water from deep reservoir levels. Also, debates emerged on whether this extreme dry condition was caused by anthropogenic influence. As part of the research efforts to understand the characteristics of extreme precipitation events causing droughts over SSP, we examine the observed and simulated precipitation datasets for the period 1961-2015 during September-October-November (SON), December-January-February (DJF), and March-April-May (MAM), respectively. Of these seasons, we focused on the mechanistic analysis in Figs. 7, 8, 9, 10 and 11 only on DJF (austral summer) because this season's precipitation is important to the mean climate over the region. The results of the analysis are summarized hereafter.

The model simulations show the ability to simulate the interannual variability of observed normalized precipitation anomaly over SSP, but with magnitude biases. For most of the time, the observed series is within the ensemble spread, while the ensemble mean which represents the externally forced climate signals alternates with the variability of observed normalized precipitation anomaly. Similarly, the model tends to simulate the spatial patterns of observed normalized seasonal precipitation anomaly, although there are biases in structure, orientation, and magnitude, which suggests that the dynamics that produce droughts in the model are biased.

The composite anomalies of the ERA-20C VIMFC and its components (moisture convergence, moisture advection, and residual terms) during 1961-2010 austral summer drought events show that anomalous moisture convergence dominates the spatial structure of the VIMFC anomaly. This suggests that the dynamics of the drought events over SSP is mainly related to significant changes in moisture convergence with significant contribution from the advection term. The reduced moisture convergence anomaly over SSP is associated with upper-level convergence and lower-level divergence, indicating the dominant role of lower tropospheric circulation changes in moisture transport. These dynamical features are related to stable atmospheric conditions and can explain the lack of convection inducing precipitation deficits.

The austral summer drought episodes during 1961-2010 can be explained by the regional meridional Hadley circulation with anomalous subsidence with a deep core at the
250-700 hPa level centered over the latitudinal domain of SSP and the associated anomalous ascending motion along the northern part of SSP. The subsidence depicts favorable conditions for upper-level convergence and low-level divergence; a good ingredient for drying over the region resulting from lack of convection. The results show that Historical simulations can reproduce the changes in the vertical motion, but there are biases in magnitude and spatial extent of the subsidence motions, consistent with the simulated precipitation distribution.

The change in atmospheric moisture content during droughts is supported by changes in the atmospheric circulation features. The DJF drought events are characterized by weak low-level wind magnitude over the North Atlantic, weak circulation anomaly (wind vectors) over the Amazon and the Andes, and moderate westerly trade winds over northeast Brazil. These anomalous circulation features deprive SSP of moisture supply from the Amazon basin via the northeast trade winds from the Atlantic. Also, the strong cyclonic circulation over the subtropical South Atlantic ensures that moisture is advected away from the coastal region of SSP. At $200 \mathrm{hPa}$ level, the anomalous anticyclonic circulation over northern Argentina coexists with subsidence motion and strong surface divergence to inhibit convection; this thus explains the precipitation deficit over SSP. The HadGEM3-GA6 Historical simulations reproduce the spatial patterns of the upper-level circulation features. However, the magnitude of the anomalous high is too strong and further displaced south-eastward. The agreement between the observed and simulated low-level atmospheric circulation is weak.

When we examine and compare the vertical profile of the vertical velocity for the $1415 \mathrm{SD}$ and other summer droughts over SSP, we find anomalous descending vertical motion corresponding to precipitation deficit over SSP. These results indicate that the dynamics modulating precipitation variability over SSP is the same, although the degree of variability may be different. Consistent with other drought events, the model Historical simulations show intense and widespread simulated anomalous descending vertical motion during the 1415SD.

The results of this study highlight the merits and limitations of the model. Although the model is biased, it still has skills in simulating the large-scale atmospheric circulations modulating precipitation variability, leading to drought conditions over SSP.

Supplementary Information The online version contains supplementary material available at https://doi.org/10.1007/s00382-021-06091-2.

Acknowledgements This work and the co-authors were supported by the UK-Brazil Research and Innovation Partnership Fund through the Met Office Climate Science for Service Partnership (CSSP) Brazil as part of the Newton Fund. 
Open Access This article is licensed under a Creative Commons Attribution 4.0 International License, which permits use, sharing, adaptation, distribution and reproduction in any medium or format, as long as you give appropriate credit to the original author(s) and the source, provide a link to the Creative Commons licence, and indicate if changes were made. The images or other third party material in this article are included in the article's Creative Commons licence, unless indicated otherwise in a credit line to the material. If material is not included in the article's Creative Commons licence and your intended use is not permitted by statutory regulation or exceeds the permitted use, you will need to obtain permission directly from the copyright holder. To view a copy of this licence, visit http://creativecommons.org/licenses/by/4.0/.

\section{References}

Abadi AM, Oglesby R, Rowe C, Mawalagedara (2017) Evaluation of GCMs historical simulations of monthly and seasonal climatology over Bolivia. Clim Dyn. https://doi.org/10.1007/ s00382-017-3952-y

Abatan AA, Gutowski WJ Jr, Ammann CM, Kaatz L, Brown BG, Buja L, Bullock R, Fowler T, Gilleland E, Gotway JH (2017) Multiyear droughts and pluvials over Upper Colorado River basin and associated circulations. J Hydrometeor 18:799-818

Alvarez MS, Vera CS, Kiladis GN, Liebmann B (2016) Influence of the Madden Julian Oscillation on precipitation and surface air temperature in South America. Clim Dyn 46:245-262

Banacos PC, Schultz DM (2005) The use of moisture flux convergence in forecasting convective initiation: historical and operational perspectives. Wea Forecasting 20:351-366

Carvalho LMV, Jones C, Liebmann B (2002) Extreme precipitation events in southeastern South America and large-scale convective patterns in the South Atlantic Convergence Zone. J Clim 15:2377-2394

Carvalho LMV, Jones C, Liebmann B (2004) The south atlantic convergence zone: intensity, form, persistence, and relationships with intraseasonal to interannual activity and extreme rainfall. J Clim 17:88-108

Christidis N, Stott PA, Scaife AA, Arribas A, Jones GS, Copsey D, Knight JR, Tennant WJ (2013) A new HadGEM3-A-Based system for attribution of weather- and climate-related extreme events. J Clim 26:2756-2783

Ciavarella A, Christidis N, Andrews M, Groenendijk M, Rostron J, Elkington M, Burke C, Lott FC, Stott PA (2018) Upgrade of the HadGEM3-A based attribution system to high resolution and a new validation framework for probabilistic event attribution. Weather Clim Extrem 20:9-32

Coelho CAS, Cardoso DHF, Firpo MAF (2016a) Precipitation diagnostics of an exceptionally dry event in São Paulo, Brazil. Theor Appl Climatol 125:769-784

Coelho CAS, De Oliveira CP, Ambrizzi T, Reboita MS, Carpenedo CB, Campos JLPS, Tomaziello ACN, Pampuch LA, Custódio MS, Dutra LMM, Da Rocha RP, Rehbein A (2016b) The 2014 southeast Brazil austral summer drought: regional scale mechanisms and teleconnections. Clim Dyn 46:3737-3752

Da Silva GAM, Drumond A, Ambrizzi T (2011) The impact of El Niño on South American summer climate during different phases of the Pacific Decadal Oscillation. Theor Appl Climatol 106:307-319

de Davi CDM, Scanlon BR, Zhang Z, Wendland E, Yin L (2016) Reservoir storage and hydrologic responses to droughts in the Paraná River basin, south-eastern Brazil. Hydrol Earth Syst Sci 20:4673-4688

de Barros SD, Lee H, Loikith PC, Barkhordarian A, Mechoso CR (2017) Can significant trends be detected in surface air temperature and precipitation over South America in recent decades? Int J Climatol 37:1483-1493

Dee D et al (2011) The ERA-Interim reanalysis: Configuration and performance of the data assimilation system. Quart J R Meteorol Soc 137:553-597

Dufek AS, Ambrizzi T (2008) Precipitation variability in Sao Paulo State, Brazil. Theor Appl Climatol 93:167-178

Durand B, Servain J, Laurent H, Machado LAT (2005) Tropical atlantic moisture flux, convection over northeastern Brazil, and pertinence of the PIRATA network. J Clim 18:2093-2101

Ferreira NJ, Correia AA, Ramírez MCV (2004) Synoptic scale features of the tropospheric circulation over tropical South America during the WETAMC TRMM/LBA experiment. Atmósfera 17:13-30

Garreaud R, Vuille M, Clement AC (2003) The climate of the Altiplano: observed current conditions and mechanisms of past changes. Palaeogeogr Palaeoclimatol Palaeoecol 194:5-22

Garreaud RD, Vuille M, Compagnucci R, Marengo J (2009) Presentday South American climate. Palaeogeogr Palaeocl 281:180-195

Grimm AM (2003) The El Niño impact on the summer monsoon in Brazil: regional processes versus remote influences. J Clim 16(1):263-280

Harris I, Jones P, Osborn T, Lister D (2014) Updated high resolution grids of monthly climatic observations-The CRU TS3.10 dataset. Int J Climatol 34:623-642

Insel N, Poulsen CJ, Sturm C, Ehlers TA (2013) Climate controls on Andean precipitation $\delta 180$ interannual variability. J Geophys Res Atmos 118:9721-9742

Liebmann B, Jones C, Carvalho LMV (2001) Interannual variability of daily extreme precipitation events in the State of São Paulo, Brazil. J Clim 14:208-218

Liebmann B, Vera CS, Carvalho LMV, Camilloni IA, Hoerling MP, Allured D, Barros VR, Báez J, Bidegain M (2004) An observed trend in central South American precipitation. J Clim $17: 4357-4367$

Marengo JA (1992) Interannual variability of surface climate in the Amazon basin. Int J Climatol 12:853-863

Marengo JA, Liebmann B, Grimm AM, Grimm AM, Misra V, Silva Dias PL, Cavalcanti IFA, Carvalho LMV, Berbery EH, Ambrizzi T, Vera CS, Saulo AC, Nogues-Paegle J, Zipser E, Sethk A, Alvese LM (2012) Recent developments on the South American monsoon system. Int J Climatol 32:1-12

Marengo JA, Valverde MC, Obregon GO (2013) Observed and projected changes in rainfall extremes in the metropolitan area of São Paulo. Clim Res 57:61-72

Nobre CA, Marengo JA, Seluchi ME, Cuartas LA, Alves LM (2016) Some characteristics and impacts of the drought and water crisis in southeastern Brazil during 2014 and 2015. J Water Res Prot $8: 252-262$

Otto FEL, Coelho CAS, King A, Coughlan de Perez E, Wada Y, van Oldenborgh GJ, Haarsma R, Haustein K, Uhe P, van Aalst M, Aravequia JA, Almeida W, Cullen H (2015) Factors other than climate change, main drivers of 2014/15 water shortage in southeast Brazil. Bull Am Meteorol Soc 96:S35-S40

Pampuch LA, Drumond A, Gimeno L, Ambrizzi T (2016) Anomalous patterns of SST and moisture sources in the South Atlantic Ocean associated with dry events in southeastern Brazil. Int J Climatol 36:4913-4928

Pattnayak KC, Gloor E, Tindall JC, Brienen RJW, Barichivich J, Baker JCA, Spracklen DV, Cintra BBL, Coelho CAS (2018) Adding new evidence to the attribution puzzle of the recent water shortage over São Paulo (Brazil). Tellus a: Dyn Meteorol Oceanograp 70(1):1-14

Poli P, Hersbach H, Tan D, Dee D, Thépaut J.-N, Simmons A, Peubey C, Laloyaux P, Komori T, Berrisford P, Dragani R, Trémolet Y, Holm E, Bonavita M, Isaksen L, Fisher M (2013) The data assimilation system and initial performance evaluation of the ECWMF 
pilot reanalysis of the20th-century assimilation surface observations only (ERA 20C). ERA Report Series no. 14, ECWMF, pp 59

Ramírez MCV, Kayano MT, Ferreira NJ (1999) Statistical analysis of upper tropospheric vortices in the vicinity of northeast Brazil during the 1980-1989 period. Atmosfera 12:75-88

Satyamurty P, Costa CP, Manzi AO (2013) Moisture source for the Amazon Basin: a study of contrasting years. Theor Appl Climatol 111:195-209

Satyamurty P, Nobre C, Silva Dias PL (1998) South America. In: Karoly DJ, Vincent DG (eds) Meteorology of the Southern Hemisphere. American Meteorological Society, pp 119-139

Scricco IM, Coelho CAS (2019) Summer daily precipitation and wet day climatological features in southeast São Paulo, Brazil. Theor Appl Climatol 137:1997-2010

Seager R, Henderson N (2013) Diagnostic computation of moisture budgets in the ERA-Interim reanalysis with reference to analysis of CMIP-Archived atmospheric model data*. J Clim 26:7876-7901

Silva Dias MAF, Dias J, Carvalho LMV, Freitas ED, Silva Dias PL (2013) Changes in extreme daily rainfall for São Paulo, Brazil. Clim Change 116:705-722

Tedeschi RG, Collins M (2017) The influence of ENSO on South American precipitation: simulation and projection in CMIP5 models. Int J Climatol 37:3319-3339
Teixeira MS, Satyamurty P (2011) Trends in the frequency of intense precipitation events in Southern and Southeastern Brazil during 1960-2004. J Clim 24:1913-1921

Vera CS, Díaz L (2015) Anthropogenic influence on summer precipitation trends over South America in CMIP5 models. Int J Climatol 35:3172-3177

Walters D, Boutle I, Brooks M, Melvin T, Stratton R, Vosper S, Wells H, Williams K, Wood N, Allen T, Bushell A, Copsey D, Earnshaw P, Edwards J, Gross M, Hardiman S, Harris C, Heming J, Klingaman N, Levine R, Manners J, Martin G, Milton S, Mittermaier M, Morcrette C, Riddick T, Roberts M, Sanchez C, Selwood P, Stirling A, Smith C, Suri D, Tennant W, Vidale PL, Wilkinson J, Willett M, Woolnough S, Xavier P (2017) The Met Office Unified Model Global Atmosphere 6.0/6.1 and JULES global land 6.0/6.1 Configurations. Geosci Model Dev 10:1487-1520

Zilli MT, Carvalho LMV, Liebmann B, Silva Dias MA (2017) A comprehensive analysis of trends in extreme precipitation over southeastern coast of Brazil. Int J Climatol 37:2269-2279

Publisher's Note Springer Nature remains neutral with regard to jurisdictional claims in published maps and institutional affiliations. 